\section{AB0390 EFFICACY AND SAFETY OF YISAIPU, A RECOMBINANT HUMAN TUMOR NECROSIS FACTOR- $\alpha$ RECEPTOR II IGG FC FUSION PROTEIN IN CHINESE PATIENTS WITH MODERATE TO SEVERE RHEUMATOID ARTHRITIS}

R. Wu. Department of rheumatology, the First Affiliated Hospital of Nanchang University, Nanchang, China

Background: Rheumatoid arthritis (RA) is characterized by chronic autoimmune diseases of progressive synovitis and joint destruction, which can eventually lead to joint deformation and disability. A number of clinical studies showed the effectiveness of tumor necrosis factor antagonist combined with methotrexate in the treatment of RA. Yisaipu used in this study is produced by CPGC Company (Shanghai, China), which was approved to treat RA by Chinese Food and Drug Administration, in 2005, which is biosimilar of etanercept (a soluble recombinant human receptor antibody fusion protein, an immunoglobulin molecule which connects two TNF receptors (p75) to the human IgG1 FC division). Etanercept had been confirmed the effectiveness in rheumatoid arthritis already in many clinical trial. ${ }^{5-8}$ However, there is rare randomized control study published regarding Yisaipu in international journals. We conducted an open-label, randomized controlled study for 24 weeks to evaluate the efficacy and safety of Yisaipu in combination with DMARDs in comparison with low or medium dose of glucocorticoid in patients with moderate to severe RA.

Objectives: to evaluate the efficacy and safety of Yisaipu in combination with DMARDs in comparison with low or medium dose of glucocorticoid in patients with moderate to severe RA.

Methods: Eighty four patients with moderate to severe rheumatoid arthritis were randomly assigned into 4 groups: group 1: methotrexate plus Yisaipu; group 2: methotrexate plus medium-dose prednisone $(30 \mathrm{mg} / \mathrm{d}$, reduced to $15 \mathrm{mg} / \mathrm{d}$ after 2 weeks); group 3: methotrexate plus low-dose prednisone (prednisone $7.5 \mathrm{mg} / \mathrm{d}$ ); group 4: methotrexate alone. Each group was treated with MTX (12.5mg once weekly, the next day with folic acid $10 \mathrm{mg}$ ) and hydroxychloroquine sulfate $(200 \mathrm{mg}$ twice a day) concomitantly. The primary endpoint was ACR20 response rate at week 24. Secondary efficacy endpoints were ACR20, ACR50, ACR70, DAS-28, Health Assessment Questionnaire (HAQ) and EULAR remission rate at week 4, 12 and 24.

Results: At week 24, a higher proportion of patients in the group 1 and group 2 than the other two groups met the ACR20 response criteria $(85.7 \%$ in group 1 and $71.4 \%$ in group 2 vs. group 3 and group $4, P<0.05$ ). The reductions of $\mathrm{HAQ}$ at week 24 showed significant improvement in group 1 and group 2 compared to group 3 and $4(-2.96$ and -2.69 respectively, $\mathrm{P}<0.05)$. Reduction of DAS-28 in group 1 and group 2 were significantly higher than the other two groups $(P<0.05)$. The percentage of EULAR remission rate of group 1 and group 2 is significantly higher than group 3 and group 4 at week $24(47.6 \%$ in group 1, 33.3\% in group $2,23.8 \%$ in group 3 and $14.3 \%$ in group $4, \mathrm{P}<0.05$ ). There were no significant differences of adverse event among four groups.

Conclusions: Yisaipu plus MTX or GCs plus MTX in Chinese patients with moderate to severe RA is safe and effective in our study. More studies are needed to compare the long-term safety and cost-effectiveness between Yisaipu and GCs in treatment with RA.

Disclosure of Interest: None declared

DOI: 10.1136/annrheumdis-2017-eular.1867

\section{AB0391 SIMILAR PHARMACOKINETICS, SAFETY AND TOLERABILITY OF THE ADALIMUMAB BIOSIMILAR CANDIDATE BI 695501 ADMINISTERED SUBCUTANEOUSLY VIA PREFILLED SYRINGE (PFS) OR AUTOINJECTOR (AI) (VOLTAIRE ${ }^{\circledR}$-AI)}

S. Ramael ${ }^{1}$, V. Moschetti ${ }^{2}$, N. Peter ${ }^{2}$, I. Sonderegger ${ }^{2}$, S. Wiebe ${ }^{2}$, B. Liedert ${ }^{2}$ ${ }^{1}$ SGS Life Science Services, CPU, Antwerp, Belgium; ${ }^{2}$ Boehringer Ingelheim, Ingelheim a.R., Germany

Background: PK bioequivalence of BI 695501, an adalimumab biosimilar candidate, and the adalimumab originator was demonstrated previously VOLTAIRE $^{\circledR}$ PK: Wynne et al., Expert Opin Investig Drugs 2016:25:1361-70). Administration in chronic inflammatory diseases benefits from patient-friendly PFSs or Als, the development of which requires assessment of PK, safety, immunogenicity, and local tolerability.

Objectives: To compare PK, safety, immunogenicity, and tolerability of BI 695501 after subcutaneous (SC) injection using either a PFS or an Al.

Methods: In this 16-week randomised, single-dose, open-label, parallel-group study (NCT02606903), 40mg Bl 695501 was administered either via PFS or Al in healthy, Caucasian, male, non-athletic volunteers aged 18-65 years with body mass index (BMI) of $\geq 18$ to $\leq 30 \mathrm{~kg} / \mathrm{m}^{2}$. The study end points included $\mathrm{AUC}_{0-1032}, \mathrm{C}_{\max }$, and $\mathrm{AUC}_{0-\infty}$, analysed using an ANOVA model with fixed effects for treatment and BMI group. Safety assessment included the proportion of subjects with drug-related adverse events (AEs). Immunogenicity parameters were: proportion of subjects with binding/neutralising anti-drug antibodies (ADAs), and ADA titers.

Results: Seventy-one volunteers were randomised: PFS, $n=36 ; A I, n=35$. Key demographic and baseline characteristics were well balanced between the treatment groups. PK end point results are shown in Table 1. Estimates for $\mathrm{Al} / \mathrm{PFS}$ geometric mean (gMean) ratios were within the standard bioequivalence acceptance range $(80-125 \%)$. Mean plasma concentration-time profiles and
Table 1. PK Parameters over All Subjects for BI 695501 via PFS or Al

\begin{tabular}{|c|c|c|c|c|c|c|}
\hline \multirow[t]{2}{*}{ Parameter } & \multicolumn{2}{|r|}{ PFS } & \multicolumn{2}{|r|}{ Al } & \multirow{2}{*}{$\begin{array}{l}\text { Adjusted gMean ratio } \\
\text { (Al/PFS) }\end{array}$} & \multirow{2}{*}{$\begin{array}{l}\text { 2-sided } \\
90 \% \mathrm{Cl}^{*}\end{array}$} \\
\hline & $\mathrm{n}$ & $\begin{array}{l}\text { Adjusted } \\
\text { gMean }^{*}\end{array}$ & $\mathrm{n}$ & $\begin{array}{l}\text { Adjusted } \\
\text { gMean }^{*}\end{array}$ & & \\
\hline${ }_{0}^{\dagger}[\mu \mathrm{g} \cdot \mathrm{h} / \mathrm{mL}]$ & $35^{\ddagger}$ & 2270 & 35 & 2280 & 100.22 & $82.13,122.29$ \\
\hline $\mathrm{AUC}_{0-1032}[\mu \mathrm{g} \cdot \mathrm{h} / \mathrm{mL}]$ & $35^{\ddagger}$ & 1960 & 35 & 1960 & 100.14 & $85.15,117.76$ \\
\hline $\mathrm{C}_{\max }[\mu \mathrm{g} / \mathrm{mL}]$ & 36 & 3.76 & 35 & 4.14 & 110.19 & $96.80,125.44$ \\
\hline
\end{tabular}

${ }^{*}$ Adjusted for treatment and BMI group as fixed effects; ${ }^{\dagger}$ Based on observed last concentration values: ${ }^{\ddagger}$ AUC values could not be calculated for one subject (Subject 1001-0110), due to the lack of appropriate terminal phase (only one non-BLQ [below the limit of quantification] value in the elimination phase).

\section{Table 2. TEAEs and ASC}

\begin{tabular}{lcc}
\hline $\mathrm{n}(\%)$ & $\mathrm{PFS}(\mathrm{n}=36)$ & $\mathrm{Al}(\mathrm{n}=35)$ \\
\hline$\geq 1$ TEAE & $29(80.6)$ & $29(82.9)$ \\
$\geq 1$ TEAE related to trial drug & $16(44.4)$ & $20(57.1)$ \\
$\geq 1$ non-serious TEAE & $29(80.6)$ & $29(82.9)$ \\
$\geq 1$ serious TEAE & 0 & 0 \\
ASC* & $14(38.9)$ & $20(57.1)$ \\
Injection site erythema & $13(36.1)$ & $18(51.4)$ \\
Injection site swelling & $3(8.3)$ & $7(20.0)$ \\
Injection site induration & $1(2.8)$ & $4(11.4)$ \\
\hline
\end{tabular}

*Injection-site reactions are those events recorded within the electronic case report form "Administration site reactions" (narrow) list.

total exposure for BI 695501 administered via PFS or Al were similar over the observation period; treatment-emergent AEs (TEAEs) and administration site conditions (ASC) are shown in Table 2 .

Similar frequencies of patients tested positive for ADAs $(57.6 \%$ in the PFS group and $51.5 \%$ in the Al group), and for neutralising antibodies (33.3\%\% in the PFS group and $30.3 \%$ in the $\mathrm{Al}$ group) at the end of the study.

Conclusions: PK, safety, tolerability, and immunogenicity of BI 695501 after SC injection with a PFS or an Al were comparable.

Disclosure of Interest: S. Ramael: None declared, V. Moschetti Employee of: Boehringer Ingelheim, N. Peter Employee of: Boehringer Ingelheim, I. Sonderegger Employee of: Boehringer Ingelheim, S. Wiebe Employee of: Boehringer Ingelheim, B. Liedert Employee of: Boehringer Ingelheim DOI: 10.1136/annrheumdis-2017-eular.3507

\section{AB0392 SAFETY AND EFFECTIVENESS OF CT-P13 IN PATIENTS WITH RHEUMATOID ARTHRITIS: RESULTS FROM 24 MONTHS NATIONWIDE REGISTRY IN KOREA}

S.H. Park ${ }^{1}$, S.S. Nah ${ }^{2}$, S.H. Chang ${ }^{2}$, K.J. Kim ${ }^{3}$, K.S. Park ${ }^{3}$, S.S. Lee ${ }^{4}$ S.R. Kwon ${ }^{5}$, S.I. Lee ${ }^{6}$, C.H. Suh ${ }^{7}$, S.H. Kim ${ }^{8}$, C.N. Son ${ }^{8}$, J.K. Min ${ }^{9}$ H.R. Kim ${ }^{10}$, H.J. Beak ${ }^{11}$, H.S. Kim ${ }^{12}$, J.Y. Choe ${ }^{13}$, H.I. Yang ${ }^{14}$, M.K. Lim ${ }^{15}$ S.J. Hong ${ }^{16}$, Y.S. Kim ${ }^{17}$, J.H. Lee ${ }^{18}$, J. Suh ${ }^{19}$, S. Lee ${ }^{19}$. ${ }^{1}$ The Catholic University of Korea Seoul St.Mary's Hospital, Seoul; ${ }^{2}$ Soonchunhyang University Cheonan Hospital, Cheonan: ${ }^{3}$ The Catholic University of Korea St. Vincent's Hospital, Suwon; ${ }^{4}$ Chonnam National University Hospital, Gwangju; ${ }^{5}$ Inha University Hospital, Incheon: ${ }^{6}$ Gyeongsang National University School of Medicine, Jinju; ${ }^{7}$ Ajou University School of Medicine, Suwon; ${ }^{8}$ Keimyung University Dongsan Medial Center, Daegu; ${ }^{9}$ Bucheon St.Mary's Hospital, Bucheon; ${ }^{10}$ Konkuk University School of Medicine, Seoul; ${ }^{11}$ Gachon University Gil Medical Center, Incheon; ${ }^{12}$ The Soonchunhyang University Seoul Hospital, Seoul; ${ }^{13}$ Daegu Catholic University Medical Center, Daegu; ${ }^{14}$ Kyung Hee University Hospital at Gang Dong, Seoul; ${ }^{15}$ Eulji University School of Medicine, Daejeon; ${ }^{16}$ Kyung Hee University Medical Center, Seoul; ${ }^{17}$ Chosun University Hospital, Gwangju; ${ }^{18}$ Inje University Ilsan Paik Hospital, Goyang; ${ }^{19}$ Celltrion, Inc, Incheon, Korea, Republic Of

Background: CT-P13 is approved in both European Union and United States, and licensed for use in 79 countries around the world as a biosimilar to innovator infliximab (INX). The independent registries of CT-P13 have been conducted in a number of European countries and Korea [1].

Objectives: To evaluate safety and effectiveness of CT-P13 when administered in a real-life setting in active RA patients.

Methods: This study collected data of patients who were treated with CT-P13 from 2013 December to 2016 June. Efficacy was assessed at baseline and every 6 months thereafter using DAS28 (ESR) and/or DAS28 (CRP) and collection of adverse events (AEs) was performed. Immunogenicity was assessed at baseline, Week 30 and every year during CT-P13 treatment period.

Results: Total 125 patients were enrolled; 104 patients started treatment with CT-P13 (Naïve group) and 21 patients ( 8 from INX, 13 from other anti-TNFs) switched treatment to CT-P13 (Switching group). The mean (SD) duration since RA diagnosis was $6.5( \pm 6.85)$ years for all patients.

Of all patients treated with CT-P13, only $4.8 \%(6 / 125)$ of patients changed to other anti-TNFs. Two of six patients changed treatment within 8 month after starting CT-P13.

The proportion of patients achieving clinical remission by DAS28 (ESR/CRP) increased gradually (Figure 1). DAS28 (ESR/CRP) value decreased from baseline at 6 months and it maintained thereafter (Table 1). Switching group also showed similar results that remission rate by DAS28 (CRP) was $42.9 \%(3 / 7)$ and mean actual value was 2.85 at 12 months. 